\title{
Tuberculosis: Guía práctica para el manejo de los contactos
}

La tuberculosis (TBC) causa más muertes anualmente que cualquier otra enfermedad infecciosa y es uno de los patógenos más importantes asociados a la epidemia del Virus de Inmunodeficiencia Humana (HIV). Se estima que en el mundo se diagnosticaron alrededor de 90 millones de casos nuevos de TBC durante la década del 90' y que, de mantenerse el actual nivel de control, 30 millones de personas habrán muerto para el año 2000. Cuando un caso de TBC infecciosa es identificado, debe reportarse a la brevedad a las autoridades sanitarias que correspondan. Las personas de su entorno son quienes mayor riesgo tienen de infectarse y eventualmente progresar a formas activas de la enfermedad. Es por este motivo que los contactos deben ser rápidamente identificados, no solo para evitar su propia enfermedad sino para cortar la cadena de transmisión. De acuerdo a la intensidad de la exposición al caso índice, los contactos se dividen en tres categorías:

Alto riesgo: convivientes, contactos sociales o laborales que comparten muchas horas diarias (en general más de 6 hs.)

Moderado riesgo: Contactos frecuentes que comparten hasta 4 a 6 horas diarias

Bajo riesgo: Contactos ocasionales

Existen al menos tres factores a tener en cuenta en la evaluación de los contactos de TBC:

- La probabilidad de que el contacto se haya infectado recientemente: hecho directamente relacionado con la intensidad de la exposición.

- La probabilidad estimada de que el contacto, una vez infectado, desarrolle $T B C$ activa: Esto se relaciona no solo con la exposición sino también con características individuales del contacto.

- La probabilidad de que la cepa de M.Tuberculosis involucrada sea resistente a drogas de uso común.

Manejo de contactos de TBC infecciosa (no resistente)
PPD $>5 \mathrm{~mm}$, una vez descartada la enfermedad activa, se debe interpretar como infección reciente y el paciente debe recibir quimioprofilaxis con isoniazida.

- En los contactos de alto riesgo que presentan una PPD negativa la reacción se debe repetir, ya que la PPD puede virar hasta 12 semanas después de la exposición. Si existiera sospecha clínica se debe descartar enfermedad activa. Eventualmente estos individuos pueden ser considerados para recibir quimioprofilaxis, que podrá discontinuarse si la nueva PPD es negativa.

- Si el contacto de alto riesgo está inmunodeprimido, se recomienda aplicar la PPD junto con otros antígenos de hipersensibilidad retardada en el otro brazo. Los más comúnmente usados (testigos) son el toxoide tetánico, el antígeno de cándida y el de paperas. Una reacción negativa a todos los antígenos confirma la presencia de anergia, definida como la ausencia de reactividad debida a la inmunodepresión. Si la PPD es negativa pero alguno de los testigos da una reacción positiva se considerará como verdaderamente negativa. Los individuos anérgicos, una vez descartada la posibilidad de enfermedad activa, deben considerarse recientemente infectados y recibir quimioprofilaxis.

\section{Quimioprofilaxis con Isoniazida:}

Existe evidencia de que el tratamiento preventivo reduce o elimina los bacilos que habitan lesiones circunscriptas por el propio sistema inmune, incluso aquellas no visibles radiológicamente. Algunos estudios de seguimiento han demostrado que el efecto beneficioso de un curso de 12 meses de isoniazida (INH) administrado a individuos PPD+ persiste por períodos de hasta 20 años, por lo tanto, en ausencia de reinfección, este efecto podría durar toda la vida.

En un estudio sobre 28000 pacientes con PPD + y Rx. tórax sugestiva de lesión inicial, la terapia con INH durante 6 meses redujo la progresión

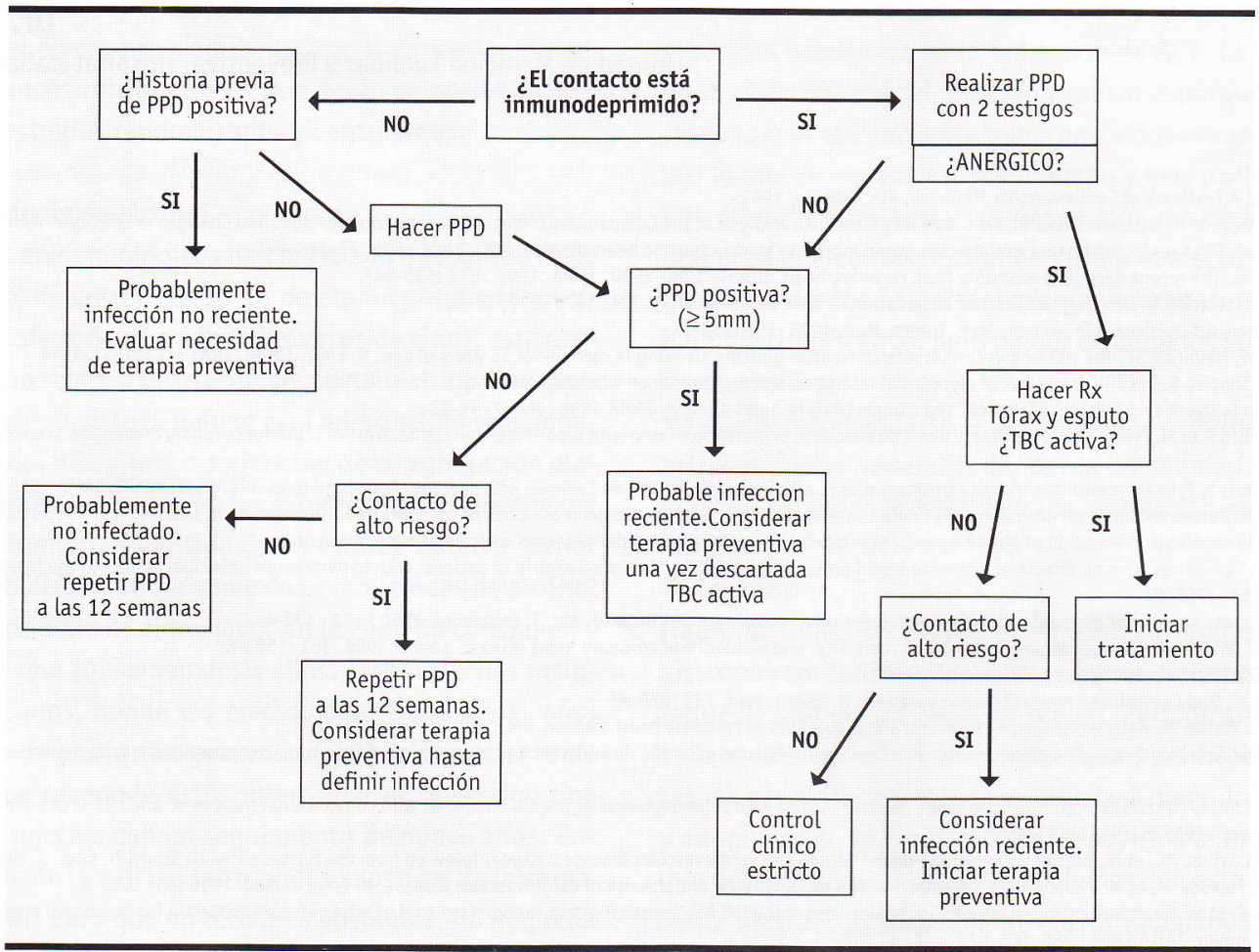

- Los contactos sin sospecha clínica de inmunodepresión y en quienes no existe o no se conoce historia de una PPD positiva en el pasado deben recibir la prueba tuberculínica y, si existe sospecha de enfermedad, radiografía de tórax y examen de esputo. Ante una a TBC activa en un $70 \%$ a los 5 años, en los individuos que cumplieron al menos con un $80 \%$ de las dosis. Otros estudios, aunque no controlados y con algunos errores de diseño, también demostraron un indiscutible beneficio con la terapia preventiva. 


\section{Recomendaciones para administrar INH profiláctica:}

PPD $>5$ mm en pacientes con HIV (La profilaxis debe durar al menos 12 meses).

PPD $>5 \mathrm{~mm}$ en contactos de alto riesgo (ver quimioprofilaxis en niños más adelante).

Riesgo de TBC activa de $10 \%$ anual.

Riesgo de 2 a $5 \%$ durante el primer año.

Conversión de PPD en el último año (>10 mm) Riesgo de 3 a $5 \%$ durante el primer año

PPD $>10 \mathrm{~mm}+$ condiciones que aumenten el riesgo de TBC: Drogadictos I.V., renales crónicos, diabetes mal controlada, desnutrición, silicosis, corticoterapia, inmunosupresion, neoplasias, etc.

La dosis recomendada es de $5 \mathrm{mg} / \mathrm{kg} /$ día (sin superar los $300 \mathrm{mg} /$ día) durante 6 a 12 meses una vez que la presencia de TBC activa haya sido descartada por Rx y eventualmente esputos seriados.

Los individuos que reciben terapia preventiva deben ser instruidos sobre la presencia de signos o síntomas de daño hepático. Estos incluyen anorexia, náuseas y vómitos, ictericia, erupción cutánea, malestar general o fiebre. Entre el 10 y el $20 \%$ de los pacientes tienen elevaciones asintomáticas de transaminasas que retornan a valores normales luego de algunas semanas.

Aproximadamente $1 \%$ de los individuos que reciben INH pueden desarrollar una enfermedad indistinguible de la hepatitis viral aguda y alrededor de la mitad de los casos ocurre durante los primeros 2 meses. La enfermedad puede ser severa, y llegar a una tasa de fatalidad cercana al $10 \%$. Además de tener en cuenta la coexistencia de sustancias hepatotóxicas que pueden potenciar a las drogas, tales como alcohol u otras drogas, uno de los factores de riesgo más importante a tener en cuenta es la edad del paciente ya que el riesgo se incrementa en forma geométrica:

$$
\begin{aligned}
<20 \text { años } & \cong 0 \% \\
20-34 & =0.3 \% \\
35-49 & =1.2 \% \\
50-64 & =2.3 \% \\
>\text { de } 65 & =5 \%
\end{aligned}
$$

Monitoreo: Se debe obtener un hepatograma basal en mayores de 35 años y un control de transaminasas cada $1-2$ meses. Es necesario suspender la INH si la GOT o GPT se elevan $\times 3$ sobre el basal o $\times 5$ sobre valores normales.

\section{Contactos de casos de TBC multiresistente:}

El surgimiento de cepas de M.Tuberculosis resistentes a las drogas de primera línea, en especial INH y luego rifampicina, se ha transformado en la gran amenaza que atenta contra la posibilidad de lograr un control de la TBC en el mundo. Se define resistencia primaria como la presencia de resistencia a una o más drogas antituberculosas en pacientes vírgenes de tratamiento; y resistencia adquirida es la que se produce en aquellos pacientes que han recibido tratamiento en algún momento de su vida durante por lo menos un mes. En general, la resistencia adquirida se produce por la falta de adherencia a los tratamientos y / o la ingestión de una sola droga (en general INH) por períodos prolongados.

En Argentina, existe una alta prevalencia de multiresistencia primaria $(4.6 \%)$ relacionada con los brotes de TBC en pacientes HIV + y otros pacientes inmunodeprimidos. La alta y preocupante tasa de multiresistencia adquirida (>22\%) nos distingue como una de las regiones del mundo con mayor prevalencia de este problema y habla del fracaso de los programas de control y tratamiento de la TBC en el país.

En pacientes inmunocomprometidos, la infección con bacilos multiresistentes evoluciona rápidamente a TBC activa con alta mortalidad. Estos bacilos se transmitirán no solo a otros pacientes inmuno comprometidos sino también a contactos inmunocompetentes que, en general, no progresan inmediatamente a enfermedad tuberculosa, pero pueden desarrollar una TBC por reactivación en algún momento de su vida y constituir otro caso de TBC multiresistente. No existe evidencia alguna de que los bacilos multiresistentes sean más virulentos que los sensibles, pero la demora en la identificación y el inicio de una terapia adecuada, de por sí dificultosa, empeora francamente el pronóstico.

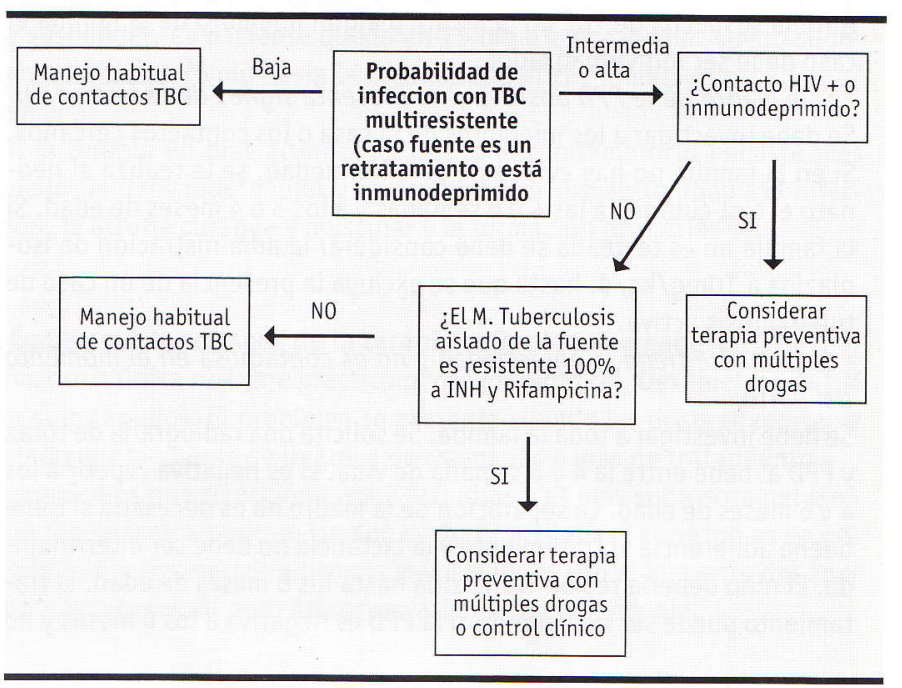

La duración de la quimioprofilaxis varía entre 6 y 12 meses. Aquellos individuos en quienes se sospecha infección con bacilos multiresistentes deben ser evaluados lo antes posible. En caso de tener riesgo moderado a alto de desarrollar $\mathrm{TBC}$, se recomiendan regímenes preventivos de al menos dos drogas. No existen datos sobre riesgo y beneficio de los esquemas preventivos que no utilizan INH o rifampicina. En pacientes no inmunodeprimidos en los que se sospecha infección con una cepa resistente $100 \%$ a INH y rifampicina (multiresistencia) habría dos opciones disponibles: 1) no dar terapia preventiva y controlar clínicamente la aparición de signos y síntomas o 2) considerar profilaxis con esquema múltiple con otras drogas, conducta no evaluada aún en estudios controlados.

Consideraciones generales en los niños: Aunque en la población pediátrica la prevalencia de TBC es menos conocida, sabemos que el patrón de infección en niños depende estrictamente del de los adultos, ya que éstos y los adolescentes se consideran el reservorio.

Exposición: Dada la baja sensibilidad de la PPD en estos grupos, los niños menores de 5 años o los niños inmunodeprimidos que hayan estado en contacto con un caso de tuberculosis deben recibir tratamiento inmediatamente con INH $5 \mathrm{mg} / \mathrm{kg} /$ día durante un mínimo de tres meses y luego realizar un segundo test cutáneo. Si la segunda PPD es negativa se suspende el tratamiento, si es positiva debe continuar 9 meses. El niño debe ser separado del caso si el mismo no está en tratamiento. Existen dos situaciones especiales: a) cuando un niño expuesto es anérgico por HIV o inmunosupresión debe ser tratado como infección tuberculosa (durante 12 meses); b) Los neonatos con madre o un miembro de la familia infectado deben ser tratados como expuestos con isoniazida y piridoxina (para evitar complicaciones neurológicas) sin necesidad de interrumpir la lactancia, siempre que la madre reciba tratamiento y controles adecuados.

Infección: Los estudios demuestran que el tratamiento con isoniazida reduce en un $90 \%$ la probabilidad de desarrollar enfermedad tuberculosa en el primer año y un efecto protector por al menos 30 años. 
Se recomienda indicar tratamiento durante 9 meses con isoniazida a los niños que presentan PPD positiva, Rx de torax normal y ninguna otra evidencia de enfermedad (infección tuberculosa). Los niños HIV positivos deben recibirlo durante un año. La INH se indica en una dosis diaria, pero cuando la adherencia familiar es baja se puede administrar dos veces por semana bajo el control de un agente de salud.

\section{Consideraciones especiales en neonatos:}

Ante la sospecha de TBC en la madre o algún miembro de la familia el caso debe ser individualizado:

- Si la madre tiene PPD positiva y no presenta signos de enfermedad: Se debe investigar a los miembros de la casa o los contactos cercanos. $\mathrm{Si}$ en la familia no hay evidencia de enfermedad, se le realiza al neonato el test cutáneo a las 406 semanas y a los 304 meses de edad. Si la familia no es testeada se debe considerar la administración de isoniazida a $10 \mathrm{mg} / \mathrm{kg} / \mathrm{d}$, hasta que se excluya la presencia de un caso de tuberculosis activa.

- Si la madre tiene la enfermedad y no es contagiosa en el momento del parto:

Se debe investigar a toda la familia. Se solicita una radiografía de tórax y PPD al bebé entre la 4 y 6 semana de vida, si es negativa repetir a los 4 y 6 meses de edad. La separación de la madre no es necesaria si tiene buena adherencia al tratamiento y la lactancia no debe ser interrumpida. El niño debería recibir isoniazida hasta los 6 meses de edad. El tratamiento puede ser suspendido si la PPD es negativa a los 6 meses y no existe ningún miembro de la familia con enfermedad activa.

- Si la madre presenta enfermedad al-momento del parto y es contagiosa:

El neonato debe ser separado hasta que la madre no sea contagiosa, luego la conducta es la misma que la anterior.

- Cuando se sospecha en la madre enfermedad diseminada (meningitis, enfermedad miliar u ósea),

En esta situación es posible la tuberculosis congénita por lo que se debe realizar al neonato una PPD y radiografía de tórax inmediatamente y comenzar tratamiento antituberculoso si se mantiene la sospecha. Si los resultados son negativos se debe separar de la madre hasta que sea no contagiosa y comenzar tratamiento con isoniazida hasta los 6 meses de edad. Luego repetir PPD, y de ser positiva continuar con el tratamiento hasta completar 9 meses.

\section{Comentario Final}

La tuberculosis es una enfermedad prevenible y tratable que se ha convertido en una epidemia de proporciones gigantescas y gravedad creciente. Entre los motivos que explican esta evolución, la biología propia de la enfermedad juega solo un pequeño papel. La estrategia de control de la TBC no puede estar basada en los centros de atención secundaria y terciaria. Es muy importante proveer a los centros de atención primaria de todo el país los recursos e infraestructura mínima necesaria para que logren hacerse cargo en forma responsable y coordinada de la identificación, tratamiento y seguimiento de la población de riesgo.

\section{Dr. Fernando Rubinstein \\ Dra. Vilda Discaciatti}

Unidad de Medicina Familiar y Preventiva. Hospital Italiano de Buenos Aires.

\section{Bibliografía recomendada}

* Boletin de la OMS 1982, 60:555 - 564

* Tuberculosis in the 1990s. Barnes P.,Barrows S. Ann Internal Med. 1993;119:400-410

* Global Epidemiology of Tuberculosis. Morbidity and Mortality of a Worldwide Epidemic. Raviglione M.;Snider D.,Kochi A. JAMA. $1995 ; 273: 220-226$

* The challenge of Tuberculosis: statements on global control and prevention. Lancet Conference. Sept 1995,346:809-819.

* Tuberculosis in the 1990s. Epidemiology and Therapeutic Challenge. Sbarbaro J. Chest 1995; 108:58s-62s.

* Jornadas sobre Tuberculosis. Ministerio de Salud y Acción Social. Argentina. Marzo-Abril 1996. Instituto Nacional de Epidemiología

"Emilio Coni".

* Rev Panam salud pública/Pan Am J Public Health 3(4), 1998

* Effect of preventive treatment for tuberculosis in adults infected with HIV: Systematic review of randomised placebo control trials. Wilkinson D, Squire SB, Garner P. BMJ 1998, 317:625-629

* Lessons from New York's tuberculosis epidemic. Coker R, BMJ 1998, 317:616

* Management of persons exposed to multidrug resistant tuberculosis. MMWR 1992,41 No RR-11

* The global threat of drug-resistant tuberculosis Snider, DE Jr, Castro KG. N Eng J Med 338 (23):1689

* Global surveillance for antituberculosis-drug resistance 1994-1997. Pablos-Mendez A, Raviglione MC, Laszlo A, et al. N Eng J Med. 338 (23):1641-1648

* American Thoracic Society Ad Hoc Committee.Treatment of Tuberculosis and Tuberculosis Infection in Adults and Children. Clinical Infectious Diseases.1995;21: 9-27.

* Jeffrey R. Starke, MD, and Armando G. Correa, MD. Management of mycobacterial infection and disease in children. Pedriatr Infec Dis J. 1995; 14: 455-470.

* Jeffrey R. Starke, MD, Richard F. Jacobs, MD, and John Jereb, MD. Resurgence of tuberculosis in children. The Journal of Pedriatrics. 1992; 120: 839-855.

* Richard F Jacobs, MD, and Rosalind S. Abernathy, MD. The treatment of tuberculosis in children. Pdriatric Infections Disease. 11985; 4: 513-517.

* Pamela Sass, MD. Tuberculosis Infection and Disease in Children. American Family Physician. 1996; 53: 2087-2094. 